ist ein Wasserzusatz nicht hierhin zu rechnen, da durch ihn alle Aschenbestandteile in gleichem Maße verändert werden, und es ist insofern nicht einzusehen, wie diese Verhältniszahl zum Nachweise einer Wässerung herangezogen werden könnte.

Was schließlich den Aschengehalt des Zuckers anbetrifft, welchem Hefelmann eine so große Bedeutung beimißt, so stimmen wir Lührig darin völlig bei, da@ dieses Bedenken für die Nahrungsmittelkontrolle durehaus belanglos erseheint, da der Aschengehalt des Zuckers für den Produzenten günstig ist. $\mathrm{Zu}$ einer ungerechten Beanstandung können wir durch ihn nicht geführt werden, sondern höchsiens zu einer unberechtigten Nichtbeanstandung. Aber vor der sind wir bekanntlich bei keinem Erzeugnis der Nahrungsmittelindustrie sicher. Trotzdem haben wir doch eine Anzahl im biesigen Handel befindlicher Zuekersorten auf Menge und Alkalität ihrer Mineralstoffe mit nachfolgendem Erfolge geprüft:

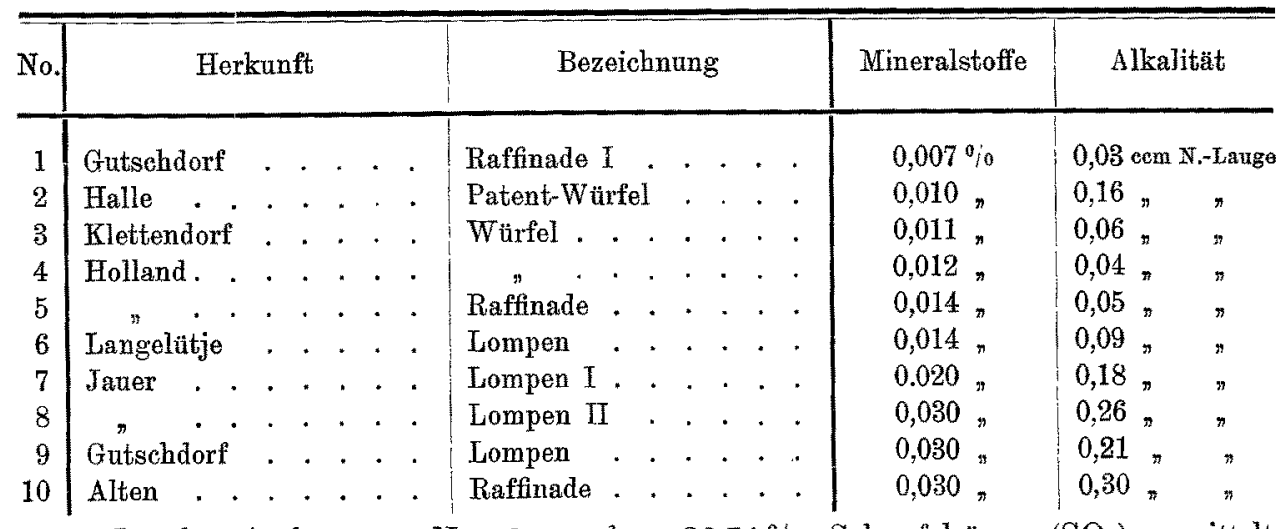

In der Asche von No. 8 wurden $32,74 \%$ Schwefelsäure $\left(\mathrm{SO}_{3}\right)$ ermittelt, während die vollständige Aschenanalyse von Nr. 10 folgende Zusammensetzung ergab. Kaliumoxyd $\left(\mathrm{K}_{2} \mathrm{O}\right)$. . . . . . . 28,96\% Calciumoxyd $(\mathrm{CaO})$. . . . . . 21,70, Sehwefelsäure $\left(\mathrm{SO}_{3}\right)$. . . . . 12,40, Magnesia $(\mathrm{MgO})$. . . . . . . 1,45" $"$ Chlor (Cl) . . . . . . . . . 0,37, Sand . . . . . . . . . . 13,33, Kohlensäure $\left(\mathrm{CO}_{2}\right)$. . . . . 22,86,

Es ergibt sich hieraus, daß die Zuckerasche im Gegensatz zu der Asche der Fruchtsäfte arm an Phosphorsäure und Alkalien, hingegen reich an Schwefelsäure und Kalk ist. Im übrigen kann bei ibrer geringen Menge von einer näheren Besprechung abgesehen werden.

\title{
Beiträge zur Kenntnis des Himbeersaftes.
}

Von

\section{A. Juckenack.}

Mitteilung aus der Statichen Anstalt zur Untersuchung von Nahrungsund Genubitteln sowie Gebrauchsgegenständen für den Landespolizeibezirk Berlin.

Im Laufe dieses Jahres wurden im Laboratorium der hiesigen Anstalt 11 Himbeerrohsäfte aus in der Provinz Brandenburg geernteten Himbeeren gepreßst und nach der Vergärung im Verbältnis von 13 Teilen Zucker auf 7 Teile Rohsaft zum Syrup verkocht. Das beim Verkochen verdampfte Wasser wurde dem Syrup wieder zugesetzt und darauf die Untersuchung in der üblichen Weise ausgeführt.

N. 05. 
Die Himbeeren zum Saft No. 6 stammten aus Lichterfelde, die übrigen 10 Rohsäfte aus der Umgebung von Werder und zwar aus Himbeerkulturen. Die Beeren, aus denen der Saft No. 7 hergestellt wurde, sind im Großbetriebe an einem Regentage gesammelt worden. worden.

Den Rohsäften No. 2 und 11 sind vor der Vergärung je $2 \%$ Zucker zugesetzt

Die Untersuchungsergebnisse waren folgende:

I. Himbeer-Rohsäfte (vergoren).

\begin{tabular}{|c|c|c|c|c|c|c|c|}
\hline \multirow{2}{*}{ No. } & \multirow{2}{*}{$\begin{array}{c}\text { Sperifisehes } \\
\text { Gewicht } \\
\text { bei } 15^{\circ}\end{array}$} & Fxtrakt & Mineral- & \multirow{2}{*}{$\begin{array}{l}\text { Alkalität } \\
\left(=\text { ecm } N_{\text {.- }}\right. \\
\text { Säure für } \\
100 \mathrm{~g} \text { Saft })\end{array}$} & \multirow{2}{*}{$\begin{array}{c}\text { Säure, } \\
\text { als Äpfel- } \\
\text { säure } \\
\mathrm{g} \text { in } 100 \mathrm{~g}\end{array}$} & \multicolumn{2}{|c|}{ Alkohol } \\
\hline & & \multicolumn{2}{|c|}{$\mathrm{g}$ in $100 \mathrm{~g}$} & & & $\mathrm{G}_{\theta} \mathrm{W}_{2}=\%$ & Vol.. $\%$ \\
\hline 1 & 1,0123 & 4,10 & 0,4426 & 4,86 & 1,541 & 2,01 & 2,58 \\
\hline 2 & 1,0150 & 5,25 & 0,5070 & 6,30 & 2,154 & 3,07 & 3,93 \\
\hline 3 & 1,0160 & 4,92 & 0,5196 & 6,61 & 1,883 & 1,79 & 2,30 \\
\hline 4 & 1,0157 & 4,80 & 0,4728 & 5,22 & 1,873 & 1,68 & 2,16 \\
\hline 5 & 1,0138 & 4,57 & 0,4902 & 5,72 & 1,531 & 2,24 & 2,86 \\
\hline 6 & 1,0145 & 4,62 & 0,4620 & 5,36 & 1,976 & 1,96 & 2,51 \\
\hline 7 & 1,0105 & 4,00 & 0,4478 & 5,11 & 1,544 & 2,79 & 3,56 \\
\hline 8 & 1,0090 & 3,77 & 0,4302 & 5,07 & 1,451 & 3,14 & 4,00 \\
\hline 9 & 1,0096 & 3,82 & 0,4070 & 4.21 & 1,497 & 3,14 & 4,00 \\
\hline 10 & 1,0108 & 4,22 & 0,5030 & 4.85 & 1,568 & 3,43 & 4,36 \\
\hline 11 & 1,0130 & 4,52 & 0,5108 & 5,86 & 1,729 & 2,57 & 3,28 \\
\hline
\end{tabular}

Aus diesen 11 Säften sind die nachstehenden Syrupe No. 1-11 hergestellt worden, wobei die Nummern der Syrupe aus den gleichen Rohsaft-Nummern hergestellt worden sind. Der Syrup No. 12 ist aus dem Safte von Thüringer Waldhimbeeren hergestellt worden. Das verdampfte Wasser ist bei diesem Syrup nicht wieder zugesetzt worden.

Die Untersuchungsergebnisse waren folgende:

II. Himbeer-Syrape.

\begin{tabular}{|c|c|c|c|c|c|c|c|c|}
\hline \multirow{3}{*}{ No. } & \multirow{3}{*}{$\begin{array}{c}\text { Spezifisehes } \\
\text { Cewicht } \\
\text { bei } 15^{\circ}\end{array}$} & \multicolumn{3}{|c|}{ In $100 \mathrm{~g}$ Syrup } & \multicolumn{2}{|c|}{ Auf Muttersaft berechnet } & \multirow{2}{*}{\multicolumn{2}{|c|}{ Alkohol }} \\
\hline & & \multirow{2}{*}{$\begin{array}{c}\text { Extrakt } \\
\mathrm{g}\end{array}$} & \multirow{2}{*}{$\begin{array}{l}\text { Mineral- } \\
\text { stoffe } \\
\mathrm{g}\end{array}$} & \multirow{2}{*}{$\begin{array}{l}\text { Alkalität } \\
(=\operatorname{ccm} \mathrm{N} . \\
\text { Säure) }\end{array}$} & \multirow{2}{*}{$\begin{array}{l}\text { Mineral- } \\
\text { stoffe } \\
\text { Gew. } 0 \%\end{array}$} & \multirow{2}{*}{$\begin{array}{c}\text { Alkalität } \\
(=\text { com N.- } \\
\text { Säure für } \\
100 \mathrm{~g}\end{array}$} & & \\
\hline & & & & & & & Gew. $\%$ & Vol.- $\%$ \\
\hline 1 & 1,3271 & 66,29 & 0,1776 & 1,86 & 0,5268 & 5,52 & 0,32 & 0,53 \\
\hline 2 & 1,3274 & 66,58 & 0,2088 & 2,16 & 0,6248 & 6,46 & 0,80 & 1,34 \\
\hline 3 & 1,3301 & 66,90 & 0,1752 & 2,02 & 0,5293 & 6,10 & 0,56 & 0,93 \\
\hline 4 & $1,3 \% 33$ & 67,36 & 0,1604 & 1,72 & 0,4914 & 5,27 & 0,48 & 0,80 \\
\hline 5 & 1,3320 & 67,25 & 0,1828 & 2,10 & 0,5582 & 6,41 & 0,64 & 1,07 \\
\hline 6 & 1,3357 & 67,80 & 0,1840 & 2,12 & 0,5714 & 6,58 & 0,55 & 0,93 \\
\hline 7 & 1,3330 & 67,51 & 0,1864 & 1,78 & 0,5737 & 5,48 & 0,84 & 1,41 \\
\hline 8 & 1,3298 & 66,94 & 0,1712 & 1,74 & 0,5178 & 5,31 & 0,72 & 1,20 \\
\hline 9 & 1,3328 & 67,34 & 0,1744 & 1,81 & 0,5340 & 5,54 & 0,72 & 1,20 \\
\hline 10 & 1,3360 & 68,01 & 0,1876 & 1,92 & 0.5864 & 6,00 & 0,88 & 1,48 \\
\hline 11 & 1,3405 & 68,57 & 0,2192 & 2,60 & 0,6974 & 8.27 & 0,55 & 0,93 \\
\hline 12 & 1,3620 & 71,96 & 0,2236 & 2,34 & 0,7977 & 8,35 & 0,51 & 0,87 \\
\hline
\end{tabular}

